\title{
Ribbon Plots - A Spatial Flow Analysis Tool for Stable Multiple-Channel Drainage Networks
}

\author{
D.J. Kucharska $^{\text {a }}$, M.J. Stewardson ${ }^{\text {a }}$, D.R. Ryu ${ }^{\text {a }}$, J.F. Costelloe ${ }^{\text {a }}$, N. Sims ${ }^{\text {b }}$ \\ Water Group, Department of Infrastructure Engineering, University of Melbourne, Parkville VIC 3010, \\ AUSTRALIA \\ ${ }^{\boldsymbol{b}}$ CSIRO Land and Water, Clayton South, VIC 3169, AUSTRALIA \\ Email: Danuta.kucharska@student.unimelb.edu.au
}

\begin{abstract}
Quantitative, landscape-scale hydrological and geomorphic analysis of remote, multiplechannel river reaches is hampered by a lack of representational tools, and measurement difficulty during significant flow events. A "black box" input/output modelling approach obscures spatial distribution of flow. At the other extreme, small-scale localised studies may be insufficient to identify landscape-scale emergent patterns. Fieldwork is infrequent, and often impossible during flows, and existing remote sensing tools are difficult to interpret and adjust using a monthly (or finer) resolution over a decadal timeframe.
\end{abstract}

The "Ribbon Plot" has been developed to concisely represent the spatial distribution of characteristics such as vegetation, moisture, and sediment size along pathways within a complex anastomosing system, as derived from remote-sensed data. This paper presents the concept using a limited dataset.

A Ribbon Plot is a linearised simplification of a complicated floodplain channel network. A set of plots is generated from spectral data, and arranged to reflect the study area configuration. The ribbons are read in the normal direction of flow - down the page for downstream - and in time sequence - left to right. Each image results in one set of ribbon plot columns with the same horizontal time coordinate. Colours are used to represent spectral index numerical values at each observation time.

The Ribbon Plot format can be tailored and updated for a desired study objective, using the latest available data for areal extent, spatial resolution, timespan, temporal resolution, and input source, as well as uncertainty estimation. A large amount of heterogeneous information can be compressed into a compact format, to reveal spatial or temporal patterns for interpretation by environmental scientists.

A small Ribbon Plot example has been developed using a $20 \mathrm{~km}$ x $20 \mathrm{~km}$ portion of the large and complicated Cooper Creek/Wilson River floodplain (Lake Eyre Basin, Australia), with spectral data extracted from standardised Landsat images for the period December 2003 to September 2004. The example demonstrates the distribution of NDVI responses (as a proxy for the presence of water) over time during a significant flow event, revealing patterns of differing flow durations and areas of increased persistence.

Keywords: $\quad$ Multiple-channel rivers, drainage networks, flow spatial distribution, remote sensing 


\section{INTRODUCTION AND BACKGROUND}

\subsection{Anastomosing Dryland Rivers}

In ephemeral dryland, or semi-arid areas, rivers are a particularly capricious water resource, with flows dependant on distant or episodic rainfall, and affected by evapotranspiration and vegetation variation. In their temporary and/or anastomosed forms, they play an important role in supporting diverse ecological and human communities, as observed by Bunn (2006), Fisher (1982) and Greet et al (2011). The inundation extent, frequency and persistence deriving from small-to-medium flows are particularly vulnerable to baseflow and climate change and human intervention, with significant ecological consequences. However, much remains to be understood about these complicated systems. Even the basic tools for observing, describing and modelling the hydrology of anastomosed floodplains, at a range of ecosystem scales, are lacking, as identified by Tooth (2009).

A major challenge exists in describing and simulating flow paths of complicated anastomosing floodplains, such as those occurring along many of Australia's arid-zone rivers. Evidence of interactions between multiple floodplain elements such as surface and shallow lateral subsurface flows, can become apparent through patterns in lead, lag and attenuation timings, storage, evaporation losses and seepage. The study of multiple, sometimes temporary, flow path systems is impeded by challenges in channel identification and representation, temporal and spatial distribution representation, monitoring of flow timings, and physical flow measurement difficulties.

A significant aggregated effect may exist when flows of varying magnitude and speed diverge, travel varying distances, and converge. Channels have been demonstrated to possess differing rise and fall flow velocities, particularly on low-gradient rivers such as the Cooper Creek. The superimposition of these flow differences at downstream convergences will result in rising and falling limb effects, potentially leading to downstream channels exceeding bankful conditions even if individual upstream flows do not attain flood thresholds.

Indeed, there is even a terminological difficulty in differentiating "floods" and "flows" on complicated ephemeral multichannel floodplains; some parts may be at overbank while other parts are still sub-bankful or dry. Isolated rainstorms can cause significant localized flows that do not extend into other parts of the floodplain. This paper will refer to "flows".

\subsection{Mapping Spatial Flow Patterns}

Spatial patterns are often represented in the literature as image "snapshots" with 2D classification of inundation area. The number of images that can be stored and manipulated simultaneously is restricted by computer storage space and processing capacity. This results in a loss of spatial resolution (if numerous images are reproduced at reduced scale) or temporal resolution (when only a small number of "snapshots" are selected for analysis). Animations of inundation are also used. These are subject to recency effects that occur when the human brain processes animations, making the most recently viewed inundation sequences appear more significant.

In both cases, quantified comparison is difficult and the storage and processing requirements for full scale image sequences can be onerous. The proposed method overcomes some of the existing difficulties with spatial representation for decadal data and landscape scales. The process for generating Ribbon Plots is described using the example of a floodplain along the Cooper Creek in South-West Queensland.

\section{FLOW SPATIAL DISTRIBUTION FOR AN ANASTOMOSED SYSTEM}

\subsection{Generation of Ribbon Plots}

Ribbon Plots are an adaptation of the Hövmoller diagram. Time is plotted along the the $\mathrm{x}$-axis, and channel segment location along the y-axis; point values of the property of interest (for example, NDVI) are drawn along vertical timelines in different colours. The method uses remote-sensed data (verified by ground-based observations) enabling relatively continuous monitoring even where site access is impossible. It may be possible to amalgamate data from a range of sources, to maximize the information that can be gathered for a sparsely-instrumented rarely-visited area. The level of detail can be varied, to more closely examine a particular area, or to take in a large spatial or temporal extent (albeit in less detail), which enables its use for a range of ecosystem scales. Flows can be monitored and analysed over time, either at a location (comparing 
an individual point over time), along a channel (comparing downstream locations over time), and across an area (comparing channel behaviours over time and space).

The method defines a simplified channel segment network to represent the complicated anastomosed drainage network, and the resultant segments are "straightened". Rather than working with a massive data cube built from consecutive remote sensing images, Ribbon Plots only store data relevant to the defined segments, which enables nimbler analysis. It is possible to repeatedly refine parts of the segment network if initial analysis indicates that more detail is needed for those parts.

\section{Ribbon Plot Methodology}

1. The floodplain is divided into channel systems depending on focus of study. An array of pixel geographical coordinates along representative flowpaths ("thals", based on the concept of a thalweg but also capturing non-channelised flows) is extracted. At this stage, the flowpaths and their corresponding pixels are selected by visual inspection of an image depicting a flow event.

2. A series of images is collated, to provide sample data for multiple dates within the timespan of the study. The image sources could vary, as long as compatible indices (such as NDVI or NDWI) can be calculated; classification of indices minimises the error that results from different sensors.

3. The band values at each location along the thals are extracted from each image in turn, and indices calculated and classified.

4. The classified indices for each thal are plotted, one per image, in a linearised format; the cumulative plot resembles a ribbon. Qualitative assessments can be made of the resulting linearised Ribbon Plots. As the representation straightens out meanders, it provides a direct comparison of actual path lengths when comparing network paths and movement of properties (moisture etc) along them.

5. To aid interpretation,the ribbon plots are arranged to reflect the channel flowpath configuration. The ribbons are generally read in the normal direction of flow - although the method can accommodate reverse flow - and in time sequence - left to right. Each image results in one set of ribbon plot columns with the same horizontal time coordinate. Colours are used to represent the index values at each observation time.

6. Quantitative analysis of the Ribbon Plots could be carried out at a point or along a single thal, or a quantitative comparison between the behaviour of different thals can be undertaken.

Figure 1 illustrates the process.

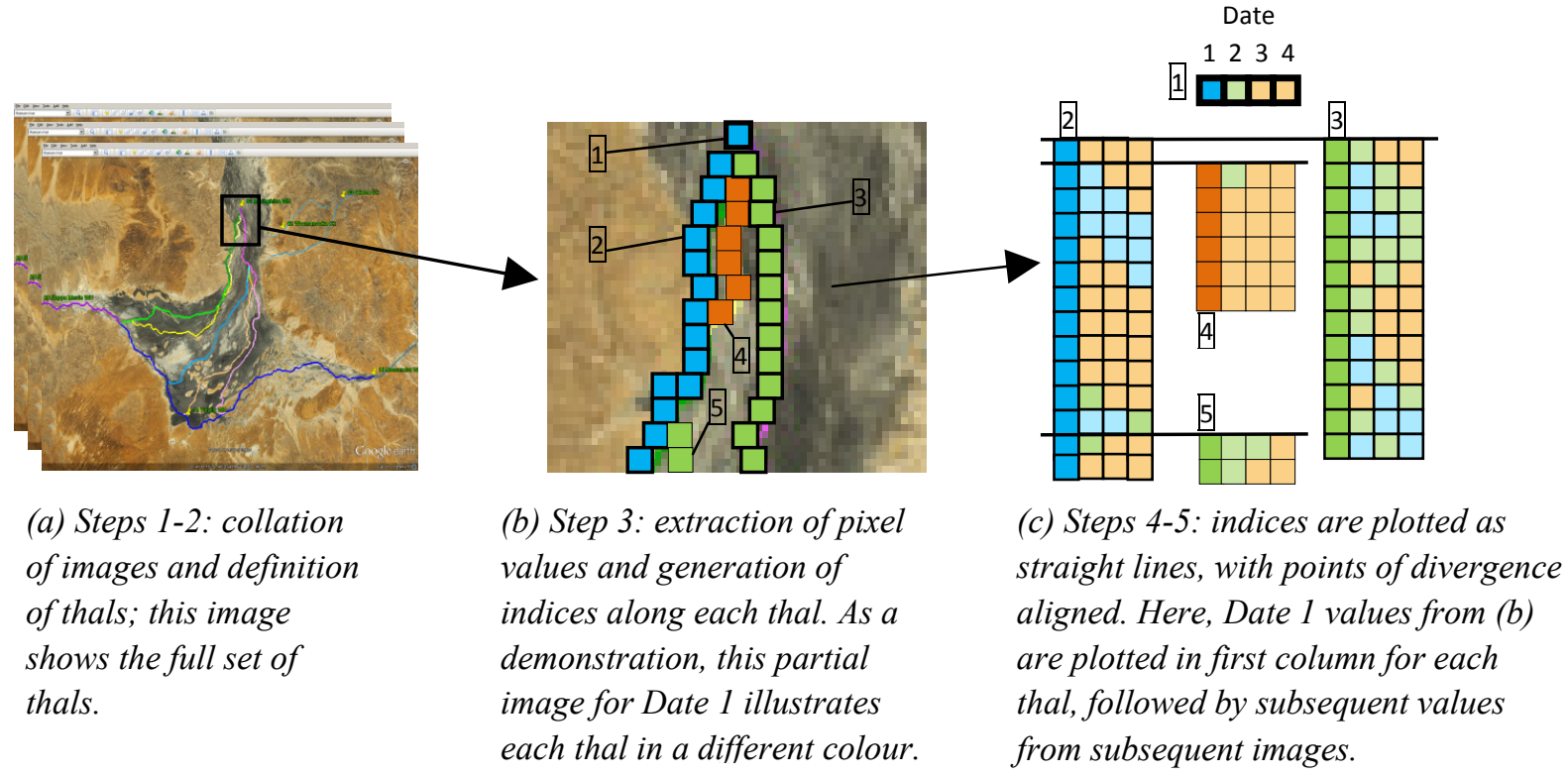

Figure 1. Step-by-step Ribbon Plot Process 


\subsection{Required Characteristics for Ribbon Plot Method}

The Ribbon Plot is most suitable for rivers with the following characteristics:

- There is an area of anastomosis, with multiple channels that ideally remain stable, as far as can be determined, over a decadal timescale, although not necessarily over longer periods. Also, ideally there is no significant human alteration of the landscape over the timespan to be studied. The method can detect drainage network changes and avulsions, and identify whether channels frequently relocate, although a new post-change set of thals would need to be defined after each relocation event, with the attendant discontinuity in the ribbon configuration.

- There is compatible remote-sensing data of a suitable temporal resolution, over the timespan to be studied. For example, forty years of fortnightly-to-monthly Landsat data, where the overlap of operational period between successive sensors provides a means of calibrating sensor differences.

- The remote-sensing data is of sufficient spatial resolution to identify flowpath centres, and is of sufficient accuracy to allow the same point to be located on successive images. The data source with the highest resolution should be used to define the pixels that make up the thals.

- The available remote-sensing data is of sufficient spectral resolution to enable the differentiation of key elements under study (for instance, turbidity levels, soil moisture, or vegetation cover) and calculation of relevant indices. The spectral resolution of data sources also needs to be compatible.

\subsection{Features and Limitations of the Ribbon Plot Process}

After assessment of the initial Ribbon Plots, additional thals can be used to increase focus, for example in areas of anastomosis; existing thals can also be divided into shorter segments. The ultimate limit is the representation of every channel segment as an individual thal. But increasing the number of ribbons makes interpretation more complicated. There is a tradeoff between ease of interpretation and the level of detail.

Selection of channels is subjective, and the criteria for choice must be based on a relevant objective characteristic. For example, this study used channel width and presence of persistent waterholes, on the not unreasonable initial assumption that this type of channel carries more significant flow than other narrower or drier channels. The selection of channels is an iterative process, and additions, adjustments, or deletions can be made as additional information becomes available. Also, using multiple images of multiple flow events would improve the channel selection process, or reveal if the initial assumption of stability was invalid.

Band value inputs can be derived from disparate sources, as corresponding geographical locations are used in the extraction. Large pixels from sources with coarser resolution could be sampled more than once if they cover multiple thal points. Data from sets of pixels could be combined to form pseudo-pixels when finer resolution sources are used. The use of indices minimizes the effects of different sensors, with nominally the same bands (red, green, blue etc). Classification further dampens the effects of resolution and sensor variability, but blurs the spectral resolution. The resulting ribbon segments are of varying data quality and uncertainty level; these attributes can be represented using the same ribbon format.

Ribbon Plots place the extracted information in the correct temporal relationship, but gaps can result for periods with no source data. It may be possible to apply statistical methods to fill data gaps using adjacent thal pixel values, noting that the interpolation affects the quality of the final ribbons.

\section{CASE STUDY : A COOPER CREEK FLOODPLAIN}

The $1500 \mathrm{~km}$ Cooper Creek system is one of the five major river systems of the endorheic Lake Eyre Basin with a catchment stretching over $306000 \mathrm{~km}^{2}$. The $900 \mathrm{~km}$ Cooper Creek proper commences at the confluence of the Thompson and Barcoo Rivers, just north of Windorah, South-west Queensland, and historically flows through to its terminus at South Australia's Lake Eyre every six years or so. Between the closest official river gauging stations at Windorah $(330 \mathrm{~km}$ upstream) and Nappa Merrie, the Cooper Creek Windorah Reach forms a wide anastamosing system known as Channel Country. The bulk of its water comes from monsoonal rains far upstream, as the mean local Class A Pan Evaporation of 2400-3600mm far exceeds the $200 \mathrm{~mm}$ local mean annual rainfall. 
Approximately $250 \mathrm{~km}$ south of Windorah, geological factors force the river sharply west, and it is joined at this bend by the ephemeral Wilson River. Downstream, the system is compressed to a single $100 \mathrm{~m}$ bedrock channel near Innamincka, South Australia. Major flows pool in the sandy region behind this constriction.

The resulting expansive low-gradient floodplain (broadly $100 \mathrm{~km} \times 75 \mathrm{~km}$, mean gradient $0.17 \mathrm{~mm} / \mathrm{km}$ ) forms the southern part of the Windorah Reach, bounded by Meringhina, Yotally, and Nappa Merrie Waterholes. The silt-covered floodplain is an example of a dryland temporary anastomosing river system. Wilson River and Cooper Creek flows intermingle on this floodplain, and some waterholes can fill from either end depending on which river is in greater spate. A map of the area with its key features is provided in Figure 2.

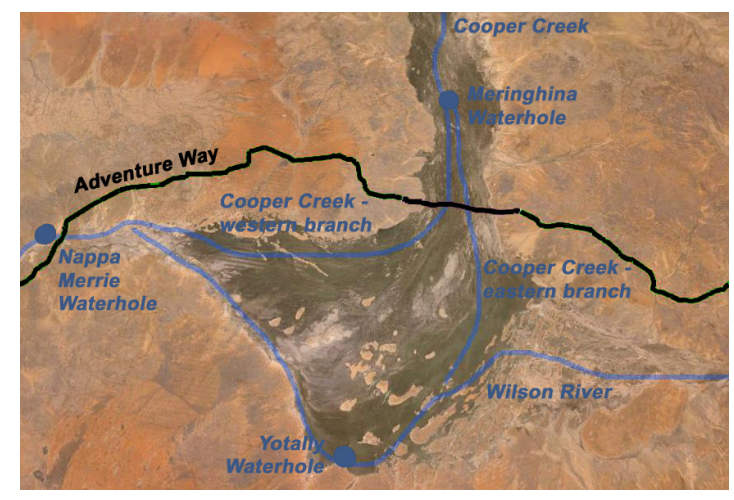

Figure 2. Cooper Creek-Wilson River Confluence and Floodplain, with key waterholes

The floodplain is crossed by Adventure Way (also known as the Jackson-Ballera Road), which joins Innamincka with the Queensland localities of Thargomindah and Noccundra. Although there is a significant human presence in the form of pastoralists, oil and gas workers and adventure tourists, the area is geographically remote, with little climate or river monitoring infrastructure. The nearest Bureau of Meteorology Reference Climate Station is over $150 \mathrm{~km}$ away at Tibooburra, although since 1990 basic weather information has been collected around the edges of the floodplain.

The area's flow regime has not been significantly modified by the agricultural, tourism and resources industries that operate within its boundaries, but the floodplain is crisscrossed by an increasing number of unsealed roads since the 1990s. Episodic flooding can cause infrastructure damage and many months of access disruptions.

In this paper, the floodplain portion under study extends from Meringhina Waterhole to Adventure Way. The study period covers December 2003 to September 2004, which includes a significant flow event.

\subsection{Flow Spatial Distribution Patterns}

The Normalized Difference Vegetation Index (NDVI) has been implemented using Landsat spectral data for the initial plots; NDVI is considered suitable for identifying responses to the presence of water in the low density vegetation of the semi-arid study area.

$$
\text { NDVI }=(\text { Near-infrared }- \text { Red }) /(\text { Near-infrared }+ \text { Red })=(\text { Band } 4-\text { Band } 3) /(\text { Band } 4+\text { Band } 3)
$$

Standardised Landsat tiles 96/79 for the study period were obtained from Queensland's Department of Environment and Resource Management. The files incorporate atmospheric correction (for the proportion of light absorbed by the atmosphere, using a fixed aerosol optical depth at 550nm of 0.05 , to convert top-ofatmosphere radiance to surface reflectance), topographic corrections (based on a bare-surface SRTM Digital Elevation Model), a bidirectional reflectance distribution function for sun/sensor angle, and geographic standardisation.

Nine thals were defined from two of the channel groups which transport water from the permanent Meringhina Waterhole, to Cooper Creek's crossing of Adventure Way. Refer to Figure 3.

\subsection{Spatial Flow Analysis for Selected Channels}

Figure 4 contain NDVI Ribbon Plots for the study area. They have been drawn in approximate relative locations to their thals, with the flow proceeding "down" the page and time increasing to the right. NDVI is used as a proxy for the presence of moisture, with greater intensities of blue and green being used to 
differentiate greater surface water and vegetation responses. This paper will focus on primary channels, during small-to-medium flows, although Fagan and Nanson (2004) discussed the possibility of shallow secondary floodway channels that flow once threshold levels are attained.

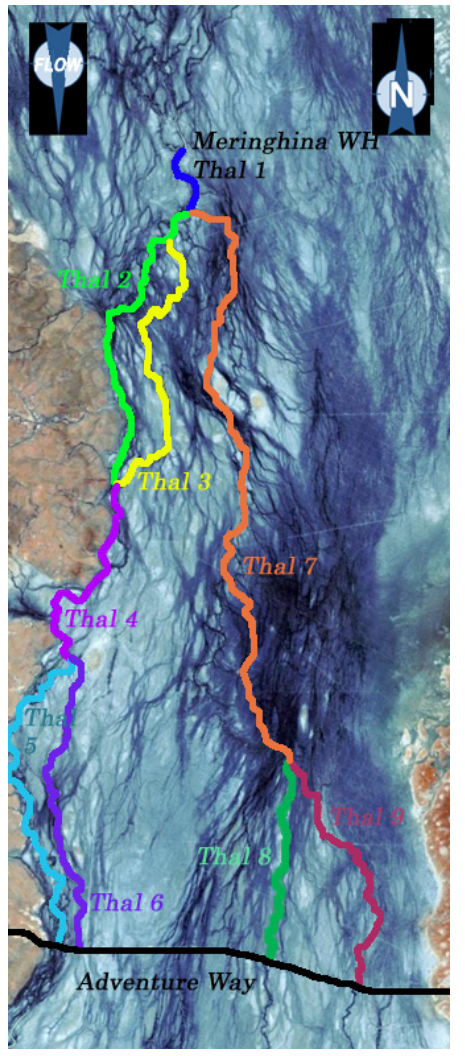

Figure 3. True colour Landsat 5 image of Cooper Creek - Meringhina Waterhole to Adventure Way, showing thals 1-9.

Figure 4. (a) Thal 1-9 Ribbons for NDVI

December 2003September 2004 (using Landsat 5 and 7). Vertical axis $0-35 \mathrm{~km}$, downstream end at 0 ; horizontal axis Days 0-300.

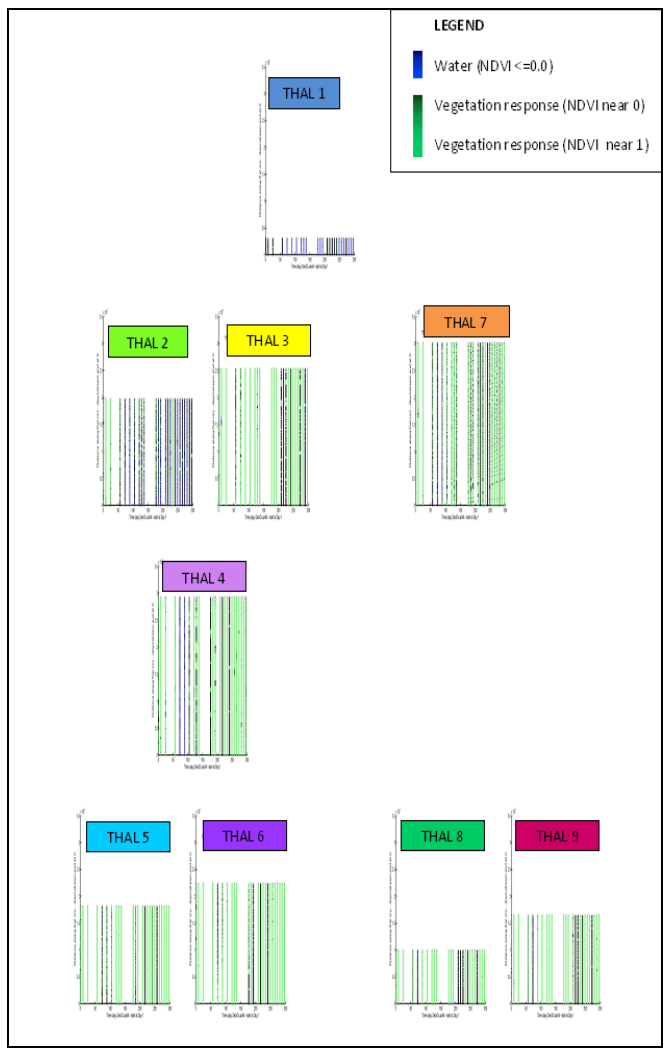

The first ribbon, Thal 1 (see Figure 3), is the permanent Meringhina Waterhole, and not unexpectedly it shows consistent presence of moisture throughout the period. NDVI numeric values are at or below zero, reflected in the intense blue, inferring deep water.

The ribbon divides into Thals 2 (light green in Figure 3) and 3 (yellow in Figure 3) in a western group, and the longer eastern Thal 7 (orange in Figure 3). Until day 55 all three are relatively dry. By days 70-90 Thals 2 and 7 show a strong water signal (negative NDVI). There is another water signal around day 190, with Thal 2 showing a noticeably stronger response along its length compared to Thal 7 .

Figure 5. Example detail - Thal 2.

Thal 3 displays a consistent strong vegetation signal (high positive NDVI), but no water signal, during the study period. The moisture response (negative NDVI or high positive NDVI) lasts longer for Thal 2 than for Thal 7, and there appears to be stretches of persistence along both.

Thals 2 and 3 join to form Thal 4 (magenta in Figure 3), which has a shorter period of water retention compared to its main feeder Thal 2 for days 70-90, and only a small water response around day 190.

Thals 5 (aqua in Figure 3) and 6 (violet in Figure 3) dividing off Thal 4, and Thals 8 (green in Figure 3 ) and 9 (maroon in Figure 3) dividing off Thal 7 show different patterns. Thal 5 appears to transmit water along its length around days 70-90, and again but more weakly around day 190. Thal 6 appears to have a strong water 
signal for days 70-90 at its upstream end that does not reach its downstream section; there was no water signal around day 190. The two easterly Thals 8 and 9 behaved similar to each other, displaying a narrower peak water response around day 70 compared to Thals 5 and 6 , and consistent vegetation response during the remaining study period.

These observations indicate the different flowpaths represented by the Thals behaved differently during the 2004 study period. The reasons for persistence along Thals 2,4 and 7 could be investigated, as could the differing responses of Thals 5 and 6 , and 8/9. If a longer study period shows these NDVI responses to be stable patterns, the information could be used for water management decision making.

\section{CONCLUSION}

The Ribbon Plots provide a summary of the hydrological history and spatial distribution of flow and dessication even for large anastamosed floodplains. Once the thals are defined for a particular study period, different indices can be investigated with little additional computation. The data that the ribbons are drawn from can be used to quantify speeds of inundation and dessication, and relative timings of flow commencement and cessation, or other changing characteristics of multiple channels, whilst maintaining the spatial relativity of the selected channel segments. Although the Ribbon Plot method has been demonstrated using a single index (NDVI) and a partial floodplain example, application and interpretation for a complete large floodplain, and optimisation of index selection and classification will benefit from further investigation.

\section{ACKNOWLEDGMENTS}

The author thanks Queensland DERM, especially Peter Scarth, for provision of standardised Landsat imagery for the study area. Appreciation is extended to Santos (Trevor Whitelaw, Andy Pietsch and the South West Queensland Team, Operations Support), Bulloo Shire (particularly Shire Engineer George Innocentes) and the Station Managers at Durham Downs, Woomanooka, Naryilco, Nappa Merrie, Nockatunga, and Orientos, for their assistance and support during the fieldwork component.

\section{REFERENCES}

Bunn, S.E. (2006). Flow variability in dryland rivers: Boom, bust and the bits in between. River Research and Applications, 22(2), 179-186.

Fagan, S.D., and Nanson, G.C. (2004). The morphology and formation of floodplain-surface channels, Cooper Creek, Australia. Geomorphology, 60(1/2), 107-126.

Fisher, S.G. (1982). Temporal succession in a desert stream ecosystem following flash flooding. Ecological Monographs, 52(1), 93-110.

Greet, J., Webb, J.A., and Cousens, R.D. (2011). The importance of seasonal flow timing for riparian vegetation dynamics: a systematic review using causal criteria analysis. Freshwater Biology, 56(7), 12311247.

Tooth, S. (2009). Arid geomorphology: emerging research themes and new frontiers. Progress in Physical Geography, 33(2), 251-287. 